\title{
A Comparative Study of the Use of Persian vs. English in Teaching English Grammar to Iranian Students in Junior High School
}

\author{
Kowsar Mehrseresht \\ English Department, Ilam Branch, Islamic Azad University, Ilam, Iran \\ E-mail: Mehrseresht125@yahoo.com \\ Habib Gowhary (Corresponding author) \\ English Department, Ilam Branch, Islamic Azad University, Ilam, Iran \\ E-mail: h_gowhary@yahoo.com \\ Akbar Azizifar \\ English Department, Ilam Branch, Islamic Azad University, Ilam, Iran \\ E-mail: Akb1354@yahoo.com
}

Doi:10.7575/aiac.alls.v.6n.4p.221

Received: $13 / 04 / 2015$

URL: http://dx.doi.org/10.7575/aiac.alls.v.6n.4p.221

Accepted: 29/06/2015

\begin{abstract}
This study compared the relationship between the use of Persian vs English in teaching English grammar to Iranian students and their achievement in learning English grammar. The participants of this study include 50 female students from a junior high school in Mehran. The researcher randomly selected 2 groups, one group was taught through the medium of Persian, while the other group was taught the same material through the medium of English. The materials were based on the content of the 3 lessons of third grade English text-book. Then a 30-item achievement test (pre-test) was administered to two groups to be getting insured of their homogeneity. The instruction began in two groups separately and the treatment lasted for 5 weeks. After the end of the instruction, the test was administered to two groups as post-test again. The data analysis showed that two languages (Persian \& English) lead to positive learning outcomes in the post-test, although the instruction through Persian caused better results than the instruction through the English.
\end{abstract}

Keywords: Teach, Grammar, English, Persian, Junior high school, Language

\section{Introduction}

One of the most controversial issues in English Language Teaching (ELT) has been the question of the use of the first language (L1) in English language classes. According to Butzkamm (2003), since the Great Reform at the end of the 19th century, the role of L1 has been second only to grammar as the most discussed methodological problem.

Reviewing the twentieth century history of ELT, one can detect violent swings of pendulum in this subject. For a long time, the use of the L1 in the EFL classroom has been a 'skeleton in the cupboard' (Prodromou, 2002). This metaphor has been used since we have for a long time treated the mother tongue as a 'taboo' subject in our field, a cause of embarrassment and on the teachers' side and a sign of their failure to teach properly, i.e., using 'only English' (Prodromou, 2002). Different methodologies have had different approaches towards the role of the students native language in English classes. For example, Grammar-Translation Method used MT as the medium of instruction while the Direct Method never allowed the use of it.

The use of L1 in ESL classes has been debated for many years. There have been many arguments about the use of L1 in L2 learning. The use of L1 has been considered as detrimental in ESL classes; on the contrary, mother tongue plays a crucial and facilitative tool in foreign learning process. The benefit of using L1 in foreign language learning has been recognized by many researchers. It should be noted that L1 remains a natural resource in L2 learning. The teacher is whether native or non-native speaker, the learner is whether beginner or advanced level, the use of L1 is whether allowed or banned, the use of L1 in ESL classes can not be avoided would gain the control of the communication.

Macaro (1997) identifies five factors to use L1 in L2 learning (adapted from Cook, 2008, p.182).

1) Using the first language for giving instructions about activities 2) Translating and checking comprehension 3) individual comments to students 4) giving feedback to pupils 5) using the first language to maintain discipline.

Harmer (2001) states that the over use of L1 restricts the students' exposure to the target language. The use of L1 to a great extent in second language learning will be a hindrance to achievement in the target language. Too much dependence on the mother tongue in ESL classes may have some disadvantages: 
1) Unless it has been translated into their native language teachers or students feel that the language items will not be understood 2) The teacher and/or the students fail to observe distinctions between equivalence of form, semantic equivalence, and pragmatic features, and thus over simplify to the point of using crude and inaccurate translation (Atkinson, 1987, p. 246).

3) Although students have the ability to express what they mean in the target language, they will speak to the teacher in their native language 4) Students will fail to realize the importance of the second language.

According to Polio and Duff (1994) an examination of classroom language has been a fruitful endeavor for applied linguists in the past decades, especially those studying the teaching and learning of English as a Second Language. Even in our country, Iran, the role of mother tongue in English classroom has been a controversial issue. Some (e.g.SiahChashm, 1995) has tried to link the failure of language learning to the use of the MT, while some others (e.g. MoradAbadi, 2003) recommend the use of the mother tongue, Persian, and translation techniques in English classes.

\subsection{Statement of the Problem}

The study was motivated by a debate in the field, in which theorists and practitioners of language teaching discuss whether L1 has a place in the language classroom. Although the call for a complete exclusion of L1 has abated, the tenor still remains that good language teaching equals a minimization of L1 use there in (e.g., Chambers, 1991). Opponents of the use of mother tongue bring forth many arguments that are meant to discourage the recourse to the mother tongue (e.g., Polio \& Duff, 1994; Harbord, 1992; Mori, 2004). Their concerns are a detrimental decline in quantity of teachers' foreign language (L2) use and subsequent lack of chances of negotiation of meaning. These factors are considered critical for language learning success. Furthermore, similar to how children absorb the language patterns of L1 around them adult FL learning is seen to take place in a same fashion. Nevertheless, no conclusive empirical evidence has been gathered to support these claims (Atkinson, 1993; Auerbach, 1994; Macaro, 1995).

Advocates of the use of L1 in FL classrooms come from a variety of viewpoints to support the use of L1.They do not argue for a regression to the traditional method of language teaching, in which the foreign language was used very rarely. However, they ask for a critical assessment of the current dominant belief that foreign language learning should take place exclusively through the medium of the target language (e.g., Atkinson, 1993). Especially, proponents of occasional use of L1 question the similarity between FL and L1 learning. They argue that students who have learned their mother tongue are sophisticated cognitive individuals who constantly refer to their L1 to make sense of the world, new concepts, and a new language. Therefore, supporters of the use of L1 propose that the rejection of L1 would only mean putting away a valuable pedagogical tool for lexical contrasting and discussion of L1/FL transferability. L1 use proponents also contend that eliminating L1 from the FL classroom would disregard the cognitive fact that connecting new concepts to already existing knowledge creates better chances for language learning achievement (Artemeva, 1995).

However, not many studies have explored the relationship between teachers' use of their L1 and their students' achievement in learning different skills of the language. Teachers may not always be aware of when and for what purpose they use L1 (Duff \& Polio, 1990; Polio \&Duff, 1994). The present study investigated the effect of the use of students' mother tongue, Persian, vs. FL, English, on the students' achievement in learning English grammar. This study took place in a foreign language context, which is characterized by students learning a language that they do not actually encounter outside of class. In the foreign language context, students and teachers share a common language. This is different from a second language context, in which students study a language in the country where the language is spoken. In such a context, they come from a variety of language backgrounds with which few teachers are familiar. Thus, the issue of using L1 is mostly relevant to the foreign language context.

\subsection{Research Hypothesis}

Regarding the purposes of the study outlined above, the following research hypothesis is posed:

1. There is no meaningful relationship between the use of Persian vs English in teaching English grammar to students in junior high school and their achievement in learning English grammar.

\subsection{Purpose of the Study}

The present study was designed to measure the effect of use of persian, participants' L1, vs English, students' foreign language, in teaching grammar on the students' achievement in learning English grammar in junior high school. Furthermore, the research examines whether any difference exist between the effect of the two languages on the students' achievement in English grammar acquisition. The medium of instruction in public school and not private language schools was of our interest, because in Iran there are differences between private language institutes and public schools regarding the syllabi, the teachers, the facilities, etc.

\section{Methodology}

\subsection{Participants}

The participants of this study include 50 female students. These students were randomly selected from Parvin junior high school in Mehran. The age range of the students is between 14 to 15 . The official language of all the students is Persian. All of them have the same background. Then researcher randomly divided them into two groups of 25 students from among 50 third grade students. 25 students were assigned to group A and the other 25 students were assigned to group $\mathrm{B}$. 


\subsection{Instrument}

The instrument used in this study was a 30-item multiple choice grammar achievement test. This test was developed by the researcher and was based on the content of the 3 lessons $(6,7,8)$ of the third grade junior high school English text-book. The content validity of the instrument was approved by three colleagues involved in teaching English as a foreign language to junior high school students. As a result the test was administered to 50 students as pre-test. Then the instruction began and there was a sufficient 5 week time distance between the pretest and posttest. After the instruction, the same test as post-test was also administered to measure the participants' achievement at the end of the treatment. It consisted of 30 questions and each lesson was examined by 10 questions. The full score of every test was 20 points.

\subsection{Procedure}

In order to conduct this study, 50 female students randomly were selected as participants from a junior high school in Mehran. The researcher randomly divided students into two groups of 25 from among 50 third grade students. 25 students were assigned to group A and the other 25 students were assigned to group B. Then a 30-item achievement test (pre-test) was administered to two groups $(\mathrm{A}, \mathrm{B})$ to be getting insured of their homogeneity.

As a result the instruction began in two groups (A,B) separately and the treatment lasted for 5 weeks. During the instruction two groups $\mathrm{A} \& \mathrm{~B}$ received the same materials which were the grammar section of third grade junior high school English text-book (lessons 6,7,8). Group A was taught through Persian and group B was taught through English.

After the end of the instruction, the test was administered to the two groups (A,B) as post- test again. Then the researcher had the scores on the post-test. Next researcher compare the mean scores of the two groups (A,B).

\section{Results and Discussion}

The statistical procedure of q-variance was used to analyze the data obtained from two groups under study. The mean scores of two groups were compared and the results of pre/post-test scores of two groups are shown in table 1and graph 1.

Table 1. The results of mean scores for pre-test \& post-test in two groups

\begin{tabular}{|c|c|c|c|c|c|c|c|c|c|c|}
\hline & \multirow[t]{2}{*}{ Groups } & \multirow[t]{2}{*}{$\mathrm{N}$} & \multicolumn{2}{|c|}{ Mean } & \multicolumn{2}{|c|}{ Std. Deviation } & \multicolumn{2}{|c|}{ Minimum } & \multicolumn{2}{|c|}{ Maximum } \\
\hline & & & Pre-t & Post- $t$ & Pre-t & Post- $t$ & Pre-t & Post-t & Pre-t & Post-t \\
\hline Junior & Persian & 25 & 6.740 & 7.650 & 2.107 & 1.877 & 3.50 & 5.50 & 10.75 & 12 \\
\hline high school & English & 25 & 6.550 & 6.810 & 1.968 & 2.010 & 3.50 & 4 & 10 & 11.50 \\
\hline
\end{tabular}

The table 3.1 shows the performance of two groups in junior high school. The mean of the Persian group in post-test was 7.650 while the mean of same group in pre-test was 6.740. So, mean of the Persian group in post-test is higher than the same group in pre-test. The mean of the English group in post-test was 6.810 while the mean of same group in pretest was 6.550 . So, mean of the English group in post-test is higher than the same group in pre-test.

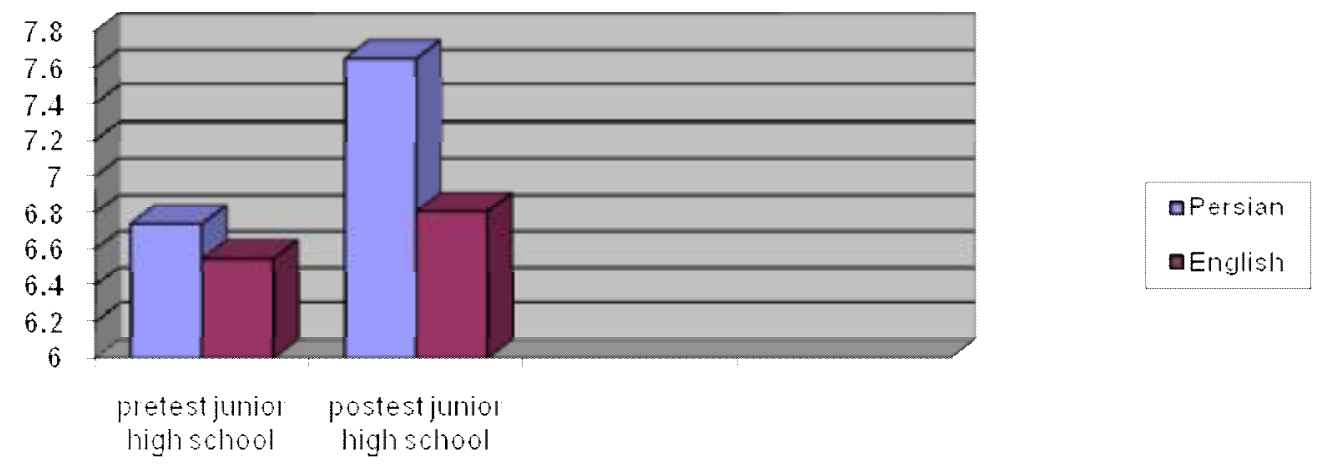

Figure 1. The results of mean scores for pre-test \& post-test in two groups

Figure 1 shows the means of the English/Persian groups in pre-test are almost equal while the means of the English/Persian groups in post-test are different.

\subsection{Results Obtained from the Pre-test}

The performance of the two groups was compared and analyzed through the statistical technique, q-variance which was based on the results of per-test scores of two groups to make sure that the two groups were almost homogenous. The results of pre-test scores of two groups are shown in table 2. 
Table 2. Analysis of the results for pre-test in two groups

\begin{tabular}{cccccc} 
& & Groups & N & Mean & Std.Deviation \\
\cline { 2 - 6 } Pre-test & & Persian & 25 & 6.740 & 2.107 \\
& Junior & English & 25 & 6.550 & 1.968 \\
& high school & & & &
\end{tabular}

The table 2 shows that the means of the Persian group is 6.740 and that of the English group 6.550. The standard deviation of the Persian group is 2.107 and that of the English group 1.968 .

So it is concluded that there is almost no significant difference between the means of Persian groups and English groups on the pre-test. This implies that the two groups had been almost homogeneous.

3.2 Results Obtained from the Post-test

After making sure about the homogeneity of two groups, the instruction began and the treatment lasted for 5 weeks in two groups. Then post-test was given to students. As a result the mean scores of two groups were compared.

Table 3. The number of participants in two groups(Persian \& English)in junior high school

\begin{tabular}{llll}
\hline & & Groups & $\mathrm{N}$ \\
\hline Instruction & 1 & Persian & 25 \\
& 2 & English & 25
\end{tabular}

Table 3 reveals that the participants of the study are 50 students. There are 25 students in Persian group and the other 25 students in English group.

Table 4. The results of mean scores of two groups (Persian \& English) in post test

\begin{tabular}{cccc}
\hline Instruction & Mean & Std. Deviation & $\mathrm{N}$ \\
\hline Persian & 7.6500 & 1.87778 & 25 \\
English & 6.8100 & 2.01075 & 25 \\
Total & 7.2300 & 1.97164 & 50 \\
\hline
\end{tabular}

Table 4 shows the results of mean scores of two groups in post test. The mean of Persian group was 7.6500 while the mean of the English group was 6.8100. So mean of the Persian group is higher than the English group.

Table 5. Analysis of the results for post-test in Persian \& English groups in junior high school

\begin{tabular}{cccccc}
\hline & Type III Sum of & & & & \\
Source & Squares & Df & Mean Square & F & Sig. \\
\hline Corrected Model & $113.759^{\mathrm{a}}$ & 2 & 56.880 & 34.845 & .000 \\
Intercept & 24.100 & 1 & 24.100 & 14.764 & .000 \\
q1 & 104.939 & 1 & 104.939 & 64.287 & .000 \\
Instruction & 6.150 & 1 & 6.150 & 3.768 & .058 \\
Error & 76.721 & 47 & 1.632 & & \\
Total & 2804.125 & 50 & & & \\
Corrected Total & 190.480 & 49 & & & \\
\hline a. $\mathrm{R} \mathrm{Squared}=.597($ Adjusted R Squared $=.580)$ \\
$(\mathrm{H}: \mathrm{B}=\circ, \mathrm{H} 1 ; \mathrm{B} \neq \circ)$
\end{tabular}

Table 5 reveals the univariate analysis of variance has given $\mathrm{F}=34.845$ which is higher than the critical $\mathrm{F}$ at $\mathrm{DF}$ of 2 $\& 47$. Therefore, $\mathrm{H} \circ$ is accepted. So, the difference found between the Persian \& English groups in junior high school is significant after students received teaching English grammar. Since, $\mathrm{F}=64.287$ and $\mathrm{P}=. / 000$ in pre-test, so instruction is an effective factor in learning grammar and students' achievement.

\section{Conclusion}

The present study designed to compare the relationship between the use of Persian vs English in teaching English grammar to Iranian students in junior high school and their achievement in learning English grammar.

Students' use of their first language knowledge can be another reason for better achievement in the Persian group. Students are sophisticated cognitive individuals who constantly draw upon their mother tongue to make sense of the world, new concepts and a new language (Atkinson,1993). It is a congnitive reality that connecting new concepts to already existing knowledge creates better chances for language learning success (Artemeva,1995). 
This study showed that the use of two languages (Persian \& English) in teaching English grammar caused positive results on students achievement in junior high school, but the students in Persian groups improved more significantly than the English groups.

\section{References}

Artemeva, N. (1995). The adult learner as incipient bilingual: The role of L1 in the adult ESL classrooms. Carleton Papers in Applied Language Studies, XII, 113-136.

Atkinson, D. (1987). The Mother Tongue in the Classroom: a Neglected Resource? ELT Journal, 44(4), pp. 241-247.

Atkinson, D. (1993). Teaching in the target language: A problem in the current orthodoxy. Language Learning Journal(8), 2-5.

Auerbach, E. R. (1994). Comments on Elsa Roberts Auerbach's 'Reexamining English only in the ESL classroom', The author responds. TESOL Quarterly, 28(1), 157-161.

Butzkamm, W. (2003). We only learn language once. The role of the mother tongue in FL Classrooms: death of a dogma. Language learning journal, 28, p. 29-39.

Chambers, G. (1991). Promoting use of the target language in the classroom. Language Learning Journal, 4, 27-31.

Cook, V. (2008). Second Language Learning and Language Teaching. London: Hodder Education.

Duff, P. \& Polio, C. (1990). How much foreign language is there in the foreign language classroom?. Modern Language Journal, 74(2), 154-166.

Harbord, J. (1992). The Use of the Mother Tongue in the Classroom. ELT Journal, 46(4), 30-55.

Harmer, J. (2001). The Practice of English Language Teaching. Edinburgh Gate: Pearson Education Ltd.

Morad-Abadi, B. (2003). The effect of translation as a facilitating factor in the teaching and learning of English on Iranian students. Alame Tabatabai University, Tehran.

Mori, R. (2004). "Staying-in-English rule revisited" System, 32, 225-236.

Polio, C. G. \& Duff, P. A. (1994). Teachers language use in university foreign language classrooms: A qualitative analysis of English and target language alternation. The Modern Language Journal, 78, 313-326.

Prodromou, L. (2002). From mother tongue to other tonge. [Electronic Version] Tesol Greece Newsletter from. http://www.tesolgreece.com/tesol-67.pdf.

Siah-Chashm, K. (1995). The precedence of teaching English through English over, teaching English through Persian. Alame Tabatabai University, Tehran. 